\title{
Identification of Surface-Exposed Protein Radicals and A Substrate Oxidation Site in A-Class Dye-Decolorizing Peroxidase from Thermomonospora curvata
}

\author{
Ruben Shrestha ${ }^{1}$, Xuejie Chen ${ }^{1, \ddagger}$, Kasra X. Ramyar $^{2, \ddagger}$, Zahra Hayati $^{3}$, Eric A. Carlson ${ }^{2}$, \\ Stefan H. Bossmann ${ }^{1}$, Likai Song ${ }^{3}$, Brian V. Geisbrecht ${ }^{2}$, and Ping Li $^{1},{ }^{*}$ \\ ${ }^{1}$ Department of Chemistry, Kansas State University, Manhattan, KS, 66506, USA \\ ${ }^{2}$ Department of Biochemistry and Molecular Biophysics, Kansas State University, Manhattan, KS, \\ 66506, USA \\ ${ }^{3}$ National High Magnetic Field Laboratory, Florida State University, Tallahassee, FL 32310, USA
}

\section{Abstract}

Dye-decolorizing peroxidases (DyPs) are a family of heme peroxidases, in which a catalytic distal aspartate is involved in $\mathrm{H}_{2} \mathrm{O}_{2}$ activation to catalyze oxidations in acidic conditions. They have received much attention due to their potential applications in lignin compound degradation and biofuel production from biomass. However, the mode of oxidation in bacterial DyPs remains unknown. We have recently reported that the bacterial TcDyP from Thermomonospora curvata is among the most active DyPs and shows activity toward phenolic lignin model compounds (J. Biol. Chem. 2015, 290, 23447). Based on the X-ray crystal structure solved at $1.75 \AA$, sigmoidal steadystate kinetics with Reactive Blue 19 (RB19), and formation of compound II-like product in the absence of reducing substrates observed with stopped-flow spectroscopy and electron paramagnetic resonance (EPR), we hypothesized that the $T c \mathrm{DyP}$ catalyzes oxidation of large-size substrates via multiple surface-exposed protein radicals. Among 7 tryptophans and 3 tyrosines in $T c$ DyP consisting of 376 residues for the matured protein, W263, W376, and Y332 were identified as surface-exposed protein radicals. Only the W263 was also characterized as one of surfaceexposed oxidation sites. SDS-PAGE and size-exclusion chromatography demonstrated that W376 represents an off-pathway destination for electron transfer, resulting in the crosslinking of proteins in the absence of substrates. Mutation of W376 improved compound I stability and overall catalytic efficiency toward RB19. While Y332 is highly conserved across all four classes of DyPs, its catalytic function in A-class $T c \mathrm{DyP}$ is minimal possibly due to its extremely small solvent accessible areas. Identification of surface-exposed protein radicals and substrate oxidation sites is

\footnotetext{
*Corresponding Author: pli@ksu.edu.

¥Author Contributions: These authors contributed equally.

Supporting Information

A list of primers for mutant plasmid construction, X-ray diffraction data collection and refinement statistics, sequence alignment, and values of solvent accessible areas for all tryptophans and tyrosines in TcDyP are provided. This material is available free of charge via the Internet at http://pubs.acs.org.

Notes

The authors declare no competing financial interest.
} 
important for understanding DyP mechanism and modulating its catalytic functions for improved activity on phenolic lignin.

\section{Abstract}

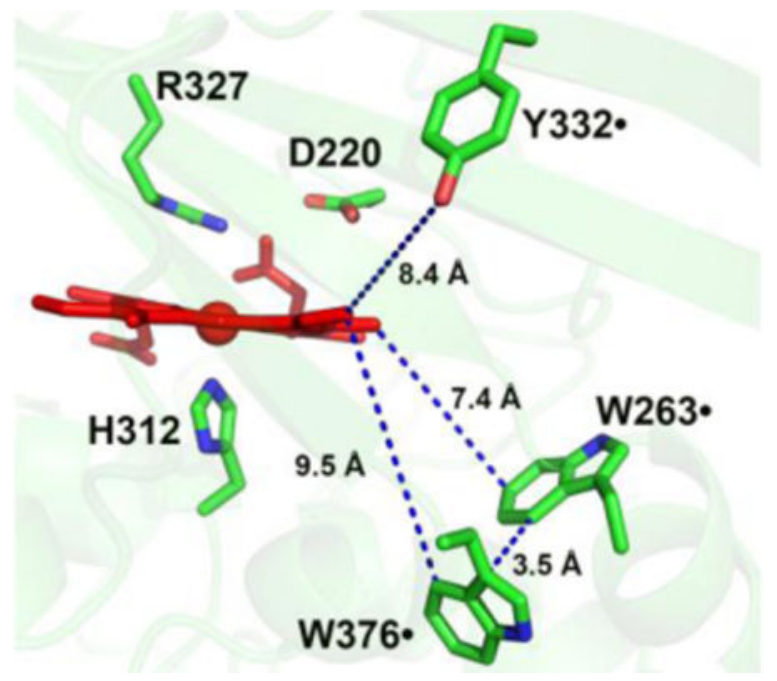

\section{Keywords}

DyP; surface-exposed; protein radical; oxidation site; crystal structure; EPR; crosslink; stoppedflow

\section{INTRODUCTION}

Dye-decolorizing peroxidases (DyPs) are a newly discovered family of heme peroxidases, which are widely present in bacterial genomes. ${ }^{1}$ While the biological function of DyPs remains unknown, they can use $\mathrm{H}_{2} \mathrm{O}_{2}$ to oxidize various industrial dyes, particularly anthraquinone derivatives that have high redox potentials and are poor substrates for classical peroxidases. ${ }^{2,3}$ DyPs have recently received much attention due to their potential application in lignin degradation, acting on the phenolic moieties. ${ }^{2,4}$ Lignin is the most abundant renewable source of aromatic polymers on earth, ${ }^{5}$ which encases cellulose and hemicellulose fibres and prevents conversion of plant biomass to bioethanol. ${ }^{6}$ However, degradation of lignin presents challenges, requiring strong acids and bases at high temperature to break it down. ${ }^{7}$ Thus, there is a growing interest in lignin degradation using enzymatic approaches. ${ }^{8}$ Studies including ours have demonstrated that DyPs can depolymerize phenolic lignin model compounds and wheat straw lignocellulose, though the efficiency is low. ${ }^{9-12}$ Thus, more structural and mechanistic works are needed for DyP in order to develop its applications in biofuel production from lignocellulose feedstock.

DyPs are subdivided into four classes, A through D, based on their primary sequences. ${ }^{13}$ Except for class D that is fungal origin, the rest are mainly from bacteria. ${ }^{13}$ It has to be noted that sequence identity between classes is very low $(<15 \%)$, especially between fungal and bacterial DyPs. ${ }^{14}$ Several fungal lignin-degrading enzymes such as lignin peroxidase (LiP) 
and versatile peroxidase (VP) have been found to oxidize substrates via surface-exposed tryptophanyl and tyrosyl radicals. ${ }^{15-17}$ Similar mode of action was also suggested for the fungal AauDyP from Auricularia auricula-judae. ${ }^{18-21}$ While such information is critical for understanding DyP mechanism and modulating its catalytic functions through protein engineering, it remains unknown for bacterial A-, B-, and C-class DyPs.

We have recently reported an A-class DyP from Thermomonospora curvata (TcDyP), which shows high peroxidase and dye-decolorizing activities. ${ }^{12}$ It is also among few DyPs that have reactivity with phenolic lignin model compounds, ${ }^{9-12}$ indicating its potential application in lignin degradation processes. The catalytic cycle of $T c$ DyP has been demonstrated to be similar to that of plant peroxidase, which incudes an enzyme resting state, compound I and compound II. ${ }^{12,22,23}$ Compound I $\left(\left[\mathrm{Fe}^{4+}=\mathrm{O}\right]^{+\bullet}\right)$ is formed by oxidation of the enzyme resting state $\left(\left[\mathrm{Fe}^{3+}\right]\right)$ with a two-electron-equivalent oxidant like $\mathrm{H}_{2} \mathrm{O}_{2}$. Reduction of Compound I with a one-electron-equivalent reducing substrate generates compound II $\left(\left[\mathrm{Fe}^{4+}=\mathrm{O}\right]\right)$, which returns to the enzyme resting state by a second one-electron-equivalent reducing substrate. It is of note that the $T c$ DyP compound I is unstable and quickly decays into compound II-like product (C2LP) in the absence of a reducing substrate. ${ }^{12}$ While A-class DyPs have a promising future in biotechnological applications, ${ }^{11,12,24}$ study on this class lags far behind the others, especially on the mode of oxidation of large-size substrates. Here we report our results to identify surface-exposed protein radicals and a substrate oxidation site involving aromatic redox-active amino acids in $T c$ DyP.

\section{MATERIALS AND METHODS}

\section{Instruments, Biochemicals, and Chemicals}

All activity assays and steady-state kinetics were performed on a Cary 100 Bio UV-Vis spectrometer equipped with temperature controller and magnetic stirring. Transient-state kinetics was carried out on an Applied Photophysics SX20 stopped-flow spectrometer equipped with sequential mixing, a PDA detector, and a monochromator. Analytical SEC was performed on a Waters Breeze 2 system equipped with a PDA detector. EPR spectra were recorded on a Bruker E680 spectrometer equipped with a high sensitivity cavity and an ESR900 helium flow cryostat from Oxford Instruments. All chemical and biochemical reagents were purchased at the highest grade and used without further purification. Protein concentrations were determined by BCA assays. ${ }^{25}$ Stocks of $\mathrm{H}_{2} \mathrm{O}_{2}$ were prepared fresh before experiments and their concentrations were determined at $240 \mathrm{~nm}$ using $\varepsilon_{240}=43.6$ $\mathrm{M}^{-1} \mathrm{~cm}^{-1}$.

\section{Protein mutation, expression and purification}

Mutations were generated using QuickChange (Agilent Technologies) according to manufacturer's instructions. Fifteen mutants were generated, which included thirteen single mutants (W158F, W194F, W237F, W244F, W263F/S/A, W376F, W396F, Y330F, Y332F/L, and Y351F), one double mutant (W263F/W376F), and one triple mutant (W158F/W237F/ W396F). Oligonucleotide primers used in the construction of these mutants are summarized in Table S1. Protein expression and purification were performed as described previously 
except that the cells were grown for an additional $4 \mathrm{~h}$ after IPTG induction. ${ }^{12}$ The mutant W263S was grown at $18{ }^{\circ} \mathrm{C}$ overnight after IPTG addition in order to reach full heme occupancy. The Reinheitszahl values $\left(R_{Z}\right)$ of purified proteins were measured to be 1.8-2.0. Their heme contents were determined to be $0.97-1.20$ using pyridine hemochromogen assays and $\Delta \varepsilon_{557-541}=20.7 \mathrm{mM}^{-1} \mathrm{~cm}^{-1} .{ }^{26}$ All mutants were analyzed by circular dichrosim to ensure that they were properly folded.

Proteins for crystallization were purified in the following way. Ten mg wild-type ( $w t$ ) $T c$ DyP were treated with $100 \mu \mathrm{g}$ subtilisin A at $37^{\circ} \mathrm{C}$ for $1 \mathrm{~h}$ before diisopropyl fluorophosphate was added to a final concentration of $100 \mu \mathrm{M}$ to stop proteolysis. Following dialysis against $20 \mathrm{mM}$ ethanolamine- $\mathrm{HCl}(\mathrm{pH} 9.0)$, the protein was subjected to ionexchange chromatography using a HiTrap Q column (GE Healthcare) and a linear gradient of $0-1.0 \mathrm{M} \mathrm{NaCl}$ in $20 \mathrm{mM}$ ethanolamine- $\mathrm{HCl}$ ( $\mathrm{pH} 9.0$ ). The eluted protein was applied to a HiPrep 26/60 Sephacryl S-200 HR column (GE Healthcare) equilibrated in $20 \mathrm{mM}$ ethanolamine- $\mathrm{HCl}$ (pH9.0) and $200 \mathrm{mM} \mathrm{NaCl}$. Fractions corresponding to dimeric TcDyP were pooled, buffer exchanged into $5 \mathrm{mM}$ ethanolamine- $\mathrm{HCl}(\mathrm{pH} 9.0)$, and concentrated to $10 \mathrm{mg} / \mathrm{ml}$ using Amicon $10 \mathrm{KDa}$ centrifugal filters.

\section{Crystallization and structure determination}

Crystals were grown by the sitting drop vapor diffusion method in a solution consisting of $100 \mathrm{mM}$ sodium succinate (pH 7.0) and 15\% (w/v) PEG3350. Crystals appeared within $24 \mathrm{~h}$ and matured by $48 \mathrm{~h}$. Individual crystals were transferred to $100 \mathrm{mM}$ sodium succinate $(\mathrm{pH}$ 7.0) containing 35\% (w/v) PEG3350, and allowed to equilibrate for 5 minutes prior to flash freezing in liquid nitrogen. Diffraction data were collected at $100 \mathrm{~K}$ using beamline 22-BM of the Advanced Photon Source, Argonne National Laboratory at a wavelength of $1.0 \AA$ and processed with the HKL2000 package. The structure was solved by molecular replacement using a PHENIX software suite with coordinates of PDB entry 4GT2 as a starting model. ${ }^{27}$ The final structure was obtained by iterative automated model building and refinement using PHENIX and interactive model modification in Coot $^{28}$ Figures were prepared using PyMol (Schrödinger, LLC). The final coordinates have been deposited in the RCSB under accession ID 5JXU.

\section{EPR samples and data collection}

EPR quartz tubes with an external diameter of $4 \mathrm{~mm}$ were used for measurements. Samples consisting of $1.0 \mathrm{mM} w t-T c D y P$ in $100 \mathrm{mM} \mathrm{NaCl}$ and $50 \mathrm{mM} \mathrm{KPi}(\mathrm{pH} 7.8)$ and $0.1 \mathrm{mM} w t-$ $T c$ DyP in $100 \mathrm{mM} \mathrm{NaCl}$ and $50 \mathrm{mM}$ sodium citrate (pH 3.0) were used for analysis of the enzyme resting state. Compound I samples were prepared by manually mixing the enzyme and 10 -fold excess $\mathrm{H}_{2} \mathrm{O}_{2}$ in EPR tubes. The mixing was conducted on ice and then the EPR tube was flash-frozen in liquid nitrogen.

X- and W-band spectra were collected at the National High Magnetic Field Laboratory (NHMFL, Tallahassee, FL). The X-band $(9.4 \mathrm{GHz})$ measurements were performed on a Bruker E680 spectrometer with a high sensitivity resonator (model No. 4119HS). The Xband spectra were collected at $5 \mathrm{~K}$ with a $4000 \mathrm{G}$ scan width using a $100 \mathrm{kHz}$ modulation frequency, $5 \mathrm{G}$ modulation amplitude, and a $1 \mathrm{~mW}$ microwave power. The X-band spectra 
centered at $g=2$ at $5-30 \mathrm{~K}$ were recorded using a $2 \mathrm{G}$ modulation amplitude, and a $0.2 \mathrm{~mW}$ microwave power. The W-band experiments were carried out on a $94 \mathrm{GHz}$ quasi-optical EPR spectrometer (HiPER) ${ }^{29}$ using an induction-mode cylindrical sample holder. The Wband spectra were collected with a $400 \mathrm{G}$ sweep width, a $5 \mathrm{G}$ modulation amplitude, and an $800 \mathrm{~Hz}$ modulation frequency.

\section{Analysis of reactions between TcDyPs and $\mathrm{H}_{2} \mathrm{O}_{2}$ by SDS-PAGE and SEC}

In a $50 \mu \mathrm{L}$ solution of $50 \mathrm{mM}$ salt at different $\mathrm{pH}$ values (sodium citrate, $\mathrm{KPi}$, and Tris- $\mathrm{HCl}$ for $\mathrm{pH} 3.0-6.0,7.0-8.0$, and 9.0, respectively), $23 \mu \mathrm{M} w t-T c \mathrm{DyP}$ was incubated with $23 \mu \mathrm{M}$ $\mathrm{H}_{2} \mathrm{O}_{2}$ at room temperature for $1 \mathrm{~min}$. An aliquot of $10 \mu \mathrm{L}$ reaction mixture was withdrawn and the reaction was stopped by addition of equal volume of $2 \mathrm{X}$ Laemmli buffer followed by heating at $95^{\circ} \mathrm{C}$ for $4 \mathrm{~min}$, which was subsequently used for SDS-PAGE. For the reaction run at $\mathrm{pH} 8.0,30 \mu \mathrm{L}$ reaction mixture was withdrawn and analyzed by SEC using a BioSep SEC-S2000 HPLC column. The column was eluted with $150 \mathrm{mM} \mathrm{NaCl}$ in $50 \mathrm{mM} \mathrm{KPi} \mathrm{(pH}$ 7.5 ) at a flow rate of $0.5 \mathrm{~mL} / \mathrm{min}$. The retention volumes of molecular mass standards were as follows: aprotinin $(6.5 \mathrm{kDa}, 9.75 \mathrm{ml})$, horse cytochrome $c(12.4 \mathrm{kDa}, 9.05 \mathrm{ml})$, chicken albumin ( $44.3 \mathrm{kDa}, 7.70 \mathrm{ml})$, bovine albumin $(66 \mathrm{kDa}, 7.20 \mathrm{ml})$, yeast alcohol dehydrogenase $(150 \mathrm{kDa}, 6.85 \mathrm{ml})$, and horse apoferritin (443 kDa, $6.00 \mathrm{ml})$.

The same experiment was also carried out with $w t-T c \mathrm{DyP}$ at $\mathrm{pH} 7.8$ in the presence of $\mathrm{RB} 19$, in which $23 \mu \mathrm{M}$ enzyme was incubated with $23 \mu \mathrm{M}$ RB19 for 1 min prior to $\mathrm{H}_{2} \mathrm{O}_{2}$ addition. Controls were prepared, in which only $\mathrm{RB} 19$, or $\mathrm{H}_{2} \mathrm{O}_{2}$, or none of them was added.

Experiments of mutants and $\mathrm{H}_{2} \mathrm{O}_{2}$ were performed at $\mathrm{pH} 7.8$ and analyzed by SDS-PAGE and SEC in the same way as described above.

\section{Enzyme assays and steady-state kinetics}

The activities of $w t$ and mutant $T c$ DyPs were determined using RB19 as the substrate. Briefly, in a $480 \mu \mathrm{L}$ solution consisting of $50 \mathrm{mM}$ sodium citrate ( $\mathrm{pH} 3.0), 0.02 \mathrm{mg} / \mathrm{mL}$ bovine serum albumin (BSA), $1 \mathrm{mM} \mathrm{H}_{2} \mathrm{O}_{2}$, and $100 \mu \mathrm{M} \mathrm{RB} 19$, the purified enzyme was added to a final concentration of $50 \mathrm{nM}$ to initiate the decolorization reaction. Assays were done in triplicates. Enzyme activity was determined by measuring the initial rate of absorbance decrease at $595 \mathrm{~nm}$ using $\varepsilon_{595 \mathrm{~nm}}=10 \mathrm{mM}^{-1} \mathrm{~cm}^{-1}$.

To determine steady-state kinetic parameters, the reactions were performed in the same way as described above except that concentrations of RB19 were varied between 5 to $100 \mu \mathrm{M}$ in the presence of $1 \mathrm{mM} \mathrm{H}_{2} \mathrm{O}_{2}$, and concentrations of $\mathrm{H}_{2} \mathrm{O}_{2}$ were varied between $10 \mu \mathrm{M}$ to 1 $\mathrm{mM}$ in the presence of $100 \mu \mathrm{M}$ RB19. Rates were determined by the slopes of the initial reactions. The data obtained were fitted either to Michaelis-Menten Equation 1 or Hill Equation 2 using SigmaPlot 11. All measurements were done in triplicates.

$$
v=\frac{v_{\max }[S]}{K_{M}+[S]} \quad \text { (Eq. 1) }
$$




$$
v=\frac{v_{\max }[S]^{h}}{K_{M}+[S]^{h}}
$$

\section{Transient-state kinetics of compound I formation}

All concentrations listed here were concentrations before mixing. Stopped-flow kinetics was performed in a single mixing mode at $22{ }^{\circ} \mathrm{C}$ in $\mathrm{KPi}$ (pH 7.8 and 3.0) using $5 \mu \mathrm{M}$ enzyme and equal volume of $\mathrm{H}_{2} \mathrm{O}_{2}$ at various concentrations. All reactions were first investigated using a multiple-wavelength detector (PDA). The PDA data were analyzed using singular value decomposition with the Pro-KIV Global Analysis program provided by Applied PhotoPhysics to obtain the number of reaction intermediates and their corresponding spectra. Reactions were then monitored at a defined wavelength (the Soret band of enzyme resting state) using a monochromator to follow the formation of compound I. The monochromator data were fitted to a single exponential equation to obtain pseudo-first order rate constants $\left(k_{o b s}\right)$. Second-order rate constants of compound I formation were calculated from plots of $k_{o b s} v s . \mathrm{H}_{2} \mathrm{O}_{2}$ concentrations. All experiments were performed in triplicate.

Rates of compound I decay $\left(k_{d}\right)$ were extracted from PDA data of reactions between $5 \mu \mathrm{M}$ enzyme and $5 \mu \mathrm{M} \mathrm{H}_{2} \mathrm{O}_{2}$. Spectra extracted at a defined wavelength corresponding to the Soret band of C2LP were fitted to a single exponential equation to obtain the decay rates.

\section{RESULTS AND DISCUSSION}

\section{Overall structure of TcDyP and heme access channels}

The $T c$ DyP crystal structure was solved by molecular replacement using the DyP model from Streptomyces coelicolor (PDB entry 4GT2) as a search probe and refined to $1.75 \AA$ limiting resolution. Data collection and refinement statistics are listed in Table S2. The structure shows that $T c$ DyP exists as a homodimer, which is consistent with the molecular mass of $\sim 80 \mathrm{KDa}$ estimated from SEC. The structure of a monomer unit is depicted in Figure $1 \mathrm{~A}$, for which the dimensions are roughly $49 \AA \times 46 \AA \times 39 \AA$. TcDyP adopts a ferredoxin-like fold consisting of antiparallel $\beta$-sheets and peripheral $\alpha$-helices, which is characteristic of the DyP-type family but distinct from the classical heme peroxidases primarily made of helical proteins. ${ }^{1,14,30}$ Similar to other heme peroxidases, ${ }^{31} \mathrm{TcDyP}$ has a histidine coordinating to the heme iron as the fifth ligand at a distance of $2.1 \AA$. However, unlike classical heme peroxidases such as horseradish peroxidase (HRP),${ }^{30-32}$ which use the distal histidine to catalyze oxidation, DyPs employ an aspartate in place of the distal histidine to perform the same function. ${ }^{23}$ Such change is thought to contribute to shifting the optimal $\mathrm{pH}$ of enzyme activity from neutral conditions for HRP to acidic conditions for DyPs. ${ }^{23}$ The distal aspartate is also a part of $G X X D G$ motif, which is recognized as the fingerprint of DyPs involved in heme binding. ${ }^{33}$

As shown in Figures 1B-D, three heme access channels are present in TcDyP. Channel 1 has a diameter of $\sim 3.3 \AA$ and leads to the heme distal cavity where $\mathrm{H}_{2} \mathrm{O}_{2}$ binds to the heme iron. Thus, channel 1 is proposed as the channel for $\mathrm{H}_{2} \mathrm{O}_{2}$ to access the heme. Channel 2 has the 
largest diameter of $\sim 5.0 \AA$ among all three channels, which points to the propionate group on pyrrole ring $\mathrm{C}$. The heme propionate has been demonstrated to provide a direct electron transfer path from the porphyrin radical to a binding substrate. ${ }^{32}$ Channel 3 leads to the methyl group on pyrrole ring $\mathrm{C}$, which is much smaller than the channel 2 with a diameter of $\sim 3.5 \AA$ A. Both channels 2 and 3 are thought to serve as the tunnels for small-size substrates to access the heme prior to oxidation.

\section{Structural evidence for surface-exposed oxidation sites}

Figure 2 shows a superimposition of $T c \mathrm{DyP}$ and $A a u \mathrm{DyP}$, which reveals that their overall structures are aligned well except for a few flexible loops. Specifically, the heme center and surrounding areas are almost identical. Previousmodeling work with fungal $A a u D y P$ has predicted that even the small-sized guaiacol molecule narrowly fits into the distal cavity where the catalytic Asp and Arg residues lie. ${ }^{19}$ In addition, the widest heme access channel 2 in TcDyP is partially blocked by E293 (Figure 1C). Thus, it cannot accommodate largesize anthraquinone-based dyes such as RB19 as the substrate in the active site. Yet $T c D y P$ has shown high activity toward RB19. We therefore hypothesized that $T c$ DyP catalyzes decolorization reactions via surface-exposed oxidation sites, which requires a long-range electron transfer (LRET) from the porphyrin to redox-active amino acids located at the protein surface to form protein-based radicals.

Tyrosines and tryptophans are common redox-active amino acids, which can form radicals under oxidative conditions and have been shown to play important roles in catalysis. ${ }^{34,35}$ Understanding the exact location and nature of protein radicals and their effect on the structure and function of proteins has been the subject of intense study. ${ }^{36}$ Such examples include elucidation of roles of tyrosine and tryptophan radicals in myoglobins, cytochrome $c$ peroxidase $(C c \mathrm{P}), \mathrm{LiP}, \mathrm{VP}$, and more recently fungal DyP. ${ }^{15-21,37,38}$

DyPs are rich in tryptophans and tyrosines, ${ }^{39}$ for which their percentage can reach up to $5 \%$ of the total residues. On the basis of sequence study of the four classes of DyPs, we have concluded that, while tyrosines predominates in D-class as redox-active amino acids, tryptophans are in the majority for A-class DyPs. For example, while the D-class DyP from Coprinopsis cinerea (Uniprot A8NBN3) contains 23 tyrosines and 8 tryptophans out of 648 residues for the matured protein, A-class $T c \mathrm{DyP}$ has 7 tryptophans and 3 tyrosines in a total of 376 amino acid residues. Recent study on D-class AauDyP has shown that, out of 7 tyrosines and 4 trytophans in 448 amino acids, surface-exposed residues including Y229, Y337, and W377 are identified as potential radical sites for dye decolorization. ${ }^{18-20}$ These results suggest that DyPs may employ multiple protein radicals on the protein surface as a general strategy for oxidizing large-size substrates. Additionally, identification of these radical sites provides a starting point for protein engineering as demonstrated by the creation of a MnCcP variant (W151F/W191F) that has six-fold improved $\mathrm{Mn}^{2+}$ oxidative activity relative to $w t-\mathrm{Mn} C c \mathrm{P}^{40}$

\section{Formation of protein radicals in wt-TcDyP as observed by EPR}

The spectrum in the top panel of Figure $3 \mathrm{~A}$ indicates that the $w t-T c \mathrm{DyP}$ at $\mathrm{pH} 7.8$ predominantly existed as a rhombically distorted axial resonance at $g_{\perp} \approx 6\left(g_{y}=6.20, g_{X}=\right.$ 
5.50, and $g_{\|}=2.00$ ), corresponding to a high-spin $\mathrm{Fe}^{3+}$. The absolute difference in $g$ values $\left(\Delta g=g_{\mathrm{y}}-g_{\mathrm{x}}\right)$ at $g=6$ was used to determine the percentage of rhombicity, $R(=\Delta g / 16 \times$ $100 \%$ ), which was calculated to be $4.4 \%$ at $\mathrm{pH} 7.8$. The resonance between $g=3$ and $g=2$ suggests the presence of a small proportion of low-spin $\mathrm{Fe}^{3+}$. The signal pattern changed significantly when the EPR was recorded at $\mathrm{pH} 3.0$ (center panel in Figure 3A). A symmetrical signal was observed for high-spin $\mathrm{Fe}^{3+}$ at $g_{\perp}=6.00$. The less reactive low-spin $\mathrm{Fe}^{3+}$ species disappeared, which is consistent with the fact that DyPs are most active under acidic conditions.

To explore whether a protein-based radical was generated, the EPR spectrum was recorded for $0.1 \mathrm{mM} T c$ DyP in the presence of $1.0 \mathrm{mM} \mathrm{H}_{2} \mathrm{O}_{2}$ at $\mathrm{pH}$ 3.0. As shown in the bottom panel of Figure 3A, a radical signal with unresolved hyperfine couplings was observed at $g_{\text {/l }}$ $=2.00$, which had an overall width and peak-to-trough width of $90 \mathrm{G}$ and $19 \mathrm{G}$, respectively. The presence of a small ferric signal was attributed to either nonreactive enzyme or most probably to native enzyme that cycled back. It has been reported that protein-based radicals usually have a signal at $g=2$ with a width of $\sim 100 \mathrm{G} .{ }^{41-44}$ On the other hand, oxoferrylporphyrin radicals were shown to contain an extremely broad signal starting from $g_{\perp}=3.45$ or 3.27 to $g_{\perp}=2,{ }^{45,46}$ which was not observed in TcDyP. Furthermore, the shape and line width of $T c$ DyP signals obtained at 20 and $30 \mathrm{~K}$ (Figure 3B) are similar to the protein radicals of Synechocystis PCC6803 peroxidase-catalase recorded at $60 \mathrm{~K}$ and of turnip peroxidase isozymes recorded at $30 \mathrm{~K} .{ }^{43,44}$ Thus, the observed radical signal in the reaction between $w t-T c$ DyP and $\mathrm{H}_{2} \mathrm{O}_{2}$ (Figure $3 \mathrm{~A}$ ) is assigned as a protein-based radical, which was further confirmed with the EPR study of mutant TcDyPs at X- (Figure 3C) and W-bands (Figure 3D) described later in this paper.

Since it has been demonstrated in our recent study that the $w t-T c$ DyP compound I is unstable and quickly decays into C2LP in the absence of reducing substrates, ${ }^{12}$ we proposed that the C2LP corresponds to the observed protein-based radicals. Notably, a temperaturedependence study of $w t-T c \mathrm{DyP}$ at $\mathrm{pH} 3.0$ (Figure 3B) illustrates that the shapes of spectral lines varied from $5 \mathrm{~K}$ to $20 \mathrm{~K}$, indicating possible interactions between the protein-based radicals and ferry-ion center. This was also confirmed by microwave power saturation experiments, which showed power-dependent line shape changes at $5 \mathrm{~K}$ (data not shown). These results suggest that the formed protein-radicals are spatially close to heme, which corresponds to our findings described later in this paper.

\section{Crosslinking of wt-TcDyP}

Since many hemoproteins have been reported to undergo protein crosslinking in the presence of $\mathrm{H}_{2} \mathrm{O}_{2}$ due to formation of surface-exposed protein radicals, ${ }^{38,47,48}$ we decided to determine whether the crosslinking also occurred with $w t-T c$ DyP. Thus, reactions of $w t-$ $T c$ DyP with $\mathrm{H}_{2} \mathrm{O}_{2}$ were analyzed with SDS-PAGE and SEC.

Figure 4A shows the SDS-PAGE of $w t-T c$ DyP incubated with one equivalent $\mathrm{H}_{2} \mathrm{O}_{2}$ under various $\mathrm{pH}$ conditions. Except for the $43 \mathrm{KDa}$ band that corresponded to a TcDyP monomer, additional bands at 100 and $250 \mathrm{KDa}$ were also observed, which were assigned as a covalent dimer and oligomer, respectively. While the formation of covalent dimer and oligomer was $\mathrm{pH}$ dependent, their trends were different. The covalent dimer and oligomer contents 
reached their maximum at $\mathrm{pH} \sim 8$ and $\sim 3$, respectively. This indicated that, under an acidic condition and in the absence of a reducing substrate, the rate of formation of covalent oligomers from covalent dimers was much faster than that of covalent dimer formation from monomers. Additionally, when the experiment was carried out in the presence of RB19, the bands corresponding to covalent dimer and oligomer disappeared (lane 4 in Figure 4B), which suggested that substrate binding may prevent the protein crosslinking.

To test whether the crosslinking would affect enzyme activity, the reactions were also analyzed by SEC in the presence and absence of RB19. The native enzyme displayed a peak at $7.50 \mathrm{~mL}$ in Figure $4 \mathrm{C}$, corresponding to a $T c$ DyP dimer. When $\mathrm{H}_{2} \mathrm{O}_{2}$ was present, two additional peaks, accounting for $54 \%$ of the total peak areas, appeared at 6.39 and $5.96 \mathrm{~mL}$, corresponding to a $T c \mathrm{DyP}$ tetramer and oligomer, respectively. Peaks were isolatedand subject to enzyme activity assay using RB19. It was found that the peak consisting of tetramer and oligomer lost $\sim 30 \%$ activity compared with the dimer peak. The results agree with the gel image shown in Figure 4A, in which $\sim 30 \%$ protein exist as covalent dimer and oligomer at $\mathrm{pH}$ 8.0. When the $\mathrm{H}_{2} \mathrm{O}_{2}$ and $\mathrm{RB} 19$ were simultaneously present in the reaction, the tetramer and oligomer peaks only accounted for 6\% of total peak areas (Figure 4C), consistent with the results from SDS-PAGE (lane 4 in Figure 4B).

\section{Involvement of W376 in protein crosslinking}

Since tryptophan and tyrosine are the most common candidates of radical sites, each of them was mutated to a less oxidizable phenylalanine in $T c D y P$. It was discovered that, while the other mutants (e.g. W237F, W263F, and Y332F) displayed similar phenomena as the wt when incubated with $\mathrm{H}_{2} \mathrm{O}_{2}$ (Figures 4D-F), only the W376F mutant significantly lost its ability to form the protein crosslinks. The bands at 100 and $250 \mathrm{KDa}$ in SDS-PAGE almost disappeared when $\mathrm{W} 376 \mathrm{~F}$ was oxidized by $\mathrm{H}_{2} \mathrm{O}_{2}$ at $\mathrm{pH} 7.8$ (Figure 4D). Accordingly, when the reaction was analyzed by SEC, no peak corresponding to the tetramer and oligomer was observed (Figure 4E).

Since W376 is located on the protein surface with a large solvent accessible area (30.2 $\AA$ ), it was initially predicted to be a radical site for substrate oxidation. Unexpectedly, activity assay showed that W376F displayed a higher reactivity than the wt with RB19 (116\%, Figure 5). Thus, our data are consistent with the idea that W376 was likely to serve as a radical sink and represent an off-pathway destination for electron transfer from the heme center to the protein surface when a dye substrate is absent.

\section{Surface-exposed protein-based radicals and substrate oxidation sites involving W263 and Y332}

To identify surface-exposed substrate oxidation sites involving tryptophanyl and tyrosyl radicals, the activities of all phenylalanine mutants were determined with RB19 in the presence of $1 \mathrm{mM} \mathrm{H}_{2} \mathrm{O}_{2}$. The results are depicted in Figure 5. While all single mutants except $\mathrm{W} 263 \mathrm{~F}$ retained the $w t$ activity, the $\mathrm{W} 263 \mathrm{~F}$ mutant lost $\sim 50 \%$ its activity. Examination of TcDyP crystal structure reveals that W263 is located on the proximal side of the heme at the dimer interface, and is the closest residue to the heme among all tryptophans and tyrosines at a distance of $7.4 \AA$ A (Figure 6). Sequence alignment depicted in Figure S1 
shows that W263 is absolutely conserved in A-class DyPs, which suggests that it is functionally important and may serve as one of protein radicals for surface-exposed substrate oxidation.

To further examine the importance of W263, activities of W263F mutant were tested against a series of substrates commonly used for DyPs, which included ABTS, catechol, guaiacol, hydroquinone, and reactive blue 4 and 5. The W263F mutant retained 40-60\% of the wt activity (data not shown), consistent with the result obtained with RB19. Additionally, residues W158, W237, and W396 have large solvent exposed areas as summarized in Table S3. We therefore hypothesized that a triple mutant of these positions would magnify the activity loss if they were involved in substrate oxidation via surface-exposed protein radicals. Activity assays on the $\mathrm{W} 158 \mathrm{~F} / \mathrm{W} 237 \mathrm{~F} / \mathrm{W} 396 \mathrm{~F}$ showed that the triple mutant retained more than 90\% wt activity (Figure 5), implying that these positions are not functionally important. Thus, of all the tryptophans in $T c$ DyP, only W263 was identified as the one that participates directly in surface-exposed substrate oxidation. It has to be noted that $T c \mathrm{DyP}$ must have multiple substrate oxidation sites on the protein surface because (1) W263 mutation only resulted in 50\% loss of the wt activity; (2) W263 mutation resulted in fewer radicals than the $w t$ (Figures $3 \mathrm{C}$ and $3 \mathrm{D}$ ), which will be described in the next section; and (3) steady-state kinetics of $T c$ DyPs with RB19 displayed a sigmoidal curve, which will be discussed in the section after next.

Sequence alignment in Figure S1 has shown that Y332 is highly conserved across all four classes of DyPs. It is located at the TcDyP dimer interface on the distal side of the heme with a distance of $8.4 \AA$ (Figure 6). Additionally, this tyrosine has been proposed as a potential surface-exposed protein radical site in B- and D-class DyPs. ${ }^{18,19,49}$ As depicted in Figure 2, structural alignment of $T c \mathrm{DyP}$ (A-class) and $A a u \mathrm{DyP}$ (D-class) based on the heme cofactor reveals that the conserved tyrosines in two proteins are overlapped. The same result was obtained when structures of $T c$ DyP and $V c$ DyP from Vibrio cholerae (B-class) were aligned (data not shown). Thus, Y332 was proposed to be one of the surface-exposed protein radical sites in $T c$ DyP, which was supported by the EPR study described in the next section. To test whether Y332 could also serve as a surface-exposed oxidation site, its mutations were performed. Enzyme assays with RB19 showed that the mutants retained more than 90\% wt activity (Figure 5). While it is in contrast with $V c$ DyP, in which the tyrosine to leucine mutant abolishes enzyme activity, ${ }^{49}$ it agrees with $A a u$ DyP, in which the mutation also minimally affects enzyme activity. ${ }^{18}$ The observed weak effects of Y332 are mainly attributed to its small solvent accessible surface area $\left(2.76 \AA^{2}\right)$ relative to the tyrosine at the same position in $V c$ DyP $\left(12.47 \AA^{2}\right)$. In addition, the solvent accessible surface areas for Y330 and Y351 are extremely small at 0 and $0.67 \AA^{2}$, respectively. Their mutations resulted in increased activities toward RB19 as shown in Figure 5, which suggests that Y330 and Y351 do not participate in the formation of protein radicals for surface-exposed substrate oxidation.

\section{EPR study of mutant TcDyPs}

Since W263, W376, and Y332 were proposed to be the sites of protein-based radicals, their EPR in the presence of $\mathrm{H}_{2} \mathrm{O}_{2}$ were investigated and compared with the $w t-T c$ DyP. As 
described above, $T c$ DyP compound I is unstable and quickly decays into C2LP, which is hypothesized as protein-based radicals. If the hypothesis is true, the mutants are expected to show radical signals with decreased intensity as well as changes in their hyperfine coupling. Thus, the W263F, W376F, and $\mathrm{Y} 332 \mathrm{~F}$ mutants were incubated with $\mathrm{H}_{2} \mathrm{O}_{2}$ at $\mathrm{pH} 7.8$ and 3.0 for $8 \mathrm{~s}$ prior to being flash-frozen in liquid nitrogen. The $\mathrm{X}$-band EPR spectra are shown in Figure 3C. Similar to the $w t-T c \mathrm{DyP}$ (Figure $3 \mathrm{~A}$ ), the mutants generated fewer radicals at $\mathrm{pH}$ 7.8 (left panel, $[T c \mathrm{DyP}]=1.0 \mathrm{mM}$ ) than at $\mathrm{pH} 3.0$ (right panel, $[T c \mathrm{DyP}]=0.1 \mathrm{mM}$ ). Since the EPR samples had the same volume, were prepared in the same manner, and were measured by the same spectrometer using the same settings, the radical intensity should be directly related to the radical yield. To our expectations, all mutants except Y332F at pH 7.8 had lower radical yields than the $w t$. Compared with the $w t$ signal, small, yet significant changes of hyperfine coupling were also observed for all mutants except $\mathrm{Y} 332 \mathrm{~F}$ at $\mathrm{pH}$ 7.8. The change was much clearer at $\mathrm{pH}$ 3.0, which represents an optimal $\mathrm{pH}$ condition for TcDyP activity. At pH 7.8, Y332F had the same radical yield and shape as the $w t$, suggesting that $\mathrm{Y} 332$ does not participate in radical formation. This agrees well with the observation that the Y332 mutants and $w t$ had similar compound I decay rates $\left(k_{d}\right)$ at $\mathrm{pH} 7.8$ (Table 1), which will be discussed later.

To further characterize the radicals, W-band EPR spectra of $0.2 \mathrm{mM} w t$ and mutant $T c$ DyPs in the presence of $2.0 \mathrm{mM} \mathrm{H}_{2} \mathrm{O}_{2}$ were recorded at $\mathrm{pH} 3.0$ and $30 \mathrm{~K}$. The enzymes were incubated with $\mathrm{H}_{2} \mathrm{O}_{2}$ for $60 \mathrm{~s}$ before being flash-frozen in liquid nitrogen. As shown in Figure 3D, the $w t$ signals consist of at least two types of protein radicals: tyrosyl and tryptophanyl radicals. The Y332F mutant signals are significantly different from the $w t$ signals. Subtraction of Y332F from the wt gave spectral features of $g_{X}, g_{y}$, and $g_{Z}$ values at $2.0078,2.0049$, and 2.0025 (the dotted line in Figure 3D), respectively, which is consistent with the previous observed $g$ values for tyrosyl radicals. ${ }^{50}$ The broad peaks in Y332F, showing $g$ values ranging from 2.002 to 2.005 , were likely resulted from tryptophanyl and other unknown radicals.

Moreover, the broader EPR line shape observed at $\mathrm{pH} 3.0$ than at $\mathrm{pH} 7.8$ implies that additional radical species exist at pH3.0, most likely contributed from Y332 and possibly other residues. Overall, the EPR study of mutants supports the hypothesis that surfaceexposed W263, W376, and Y332 generate protein radicals in the presence of $\mathrm{H}_{2} \mathrm{O}_{2}$ under acidic conditions.

\section{Steady-state kinetics of W263, W376, and Y332 mutants}

To further understand the importance of W263, W376, and Y332, we conducted steady-state kinetic evaluations of a panel of site-directed mutants in the presence of $\mathrm{RB} 19$ and $\mathrm{H}_{2} \mathrm{O}_{2}$. The results are summarized in Table 1. We have recently reported that small- and large-size substrates display different kinetics with $w t-T c \mathrm{DyP},{ }^{12}$ which could be attributed to distinct oxidation sites for small- and large-size substrates. The small-size substrates like guaiacol could be oxidized at the heme center via heme access channels 2 and 3 shown in Figure 1. The large-size dye substrates such as RB19 and lignin model compounds are likely to be oxidized on the protein surface via LRET processes as described above. As depicted in Figure 7, unlike the $\mathrm{H}_{2} \mathrm{O}_{2}$ that shows the classical Michaelis-Menten kinetics, oxidation of 
RB19 by the $w t$ and mutant $T c$ DyPs displays a sigmoidal kinetics, suggesting that cooperativity exists between the enzyme and dye substrate. The estimated Hill constant $(h)$ is around three, implying that the $T c$ DyP has multiple substrate binding sites for RB19. Such phenomena were also observed for other hemoproteins. For example, hemoglobin binds four oxygen molecules at four separate sites, displaying a Hill constant of three. ${ }^{51}$ Thus, single mutations are unlikely to abolish $T c$ DyP activity.

As shown in Figure 6, not only is W263 the closest residue to the heme among all tryptophans and tyrosines, but also it forms a hydrogen bond network to D220 via M216 and N214. The D220 is a catalytic residue located in the heme distal cavity, which is characteristic of DyP enzymes and plays critical roles in compound I formation when the heme $\mathrm{Fe}^{3+}$ is oxidized by $\mathrm{H}_{2} \mathrm{O}_{2} \cdot{ }^{12}$ Additionally, W263 forms a hydrogen bond with E109 from another monomer unit, suggesting that W263 could also be involved in dimer formation of the native enzyme. To characterize the role of W263, we mutated this residue to phenylalanine, alanine, and serine. Phenylalanine was selected because it is a conservative substitution of tryptophan, but lacks of the ability to produce a stable radical and form hydrogen bonds. Alanine was chosen because it is a non-polar (hydrophobic) amino acid without aromacity, which could help reveal the importance of indole ring in W263. Serine was selected because it is a preferred substitution for tryptophans in many peroxidases, ${ }^{15,17,18}$ which may help to address polar interactions involving the indole ring. While all W263 mutants had lower catalytic efficiency than the $w t$ toward both RB19 and $\mathrm{H}_{2} \mathrm{O}_{2}$, the mutations we examined showed a much more pronounced effect on $\mathrm{H}_{2} \mathrm{O}_{2}$ consumption than on RB19 oxidation as summarized in Table 1. All W263 mutants displayed similar and increased binding affinities toward RB19 relative to the $w t(\sim 30 \%$ increase), which suggests that $\pi-\pi$ interaction is unlikely important for the binding of dye substrates, as side chains of W263S and W263A lack of aromatic rings. Moreover, their turnover numbers toward RB19 dropped half to $\sim 50 \mathrm{~s}^{-1}$, which is consistent with our expectation as the mutants will not be able to generate a stable radical. While the $w t$ and W263S had almost the same $\mathrm{H}_{2} \mathrm{O}_{2}$ affinities, W263F and W263A displayed much lower $\mathrm{H}_{2} \mathrm{O}_{2}$ affinities than the $w t$. In addition, the turnover number of W263S toward $\mathrm{H}_{2} \mathrm{O}_{2}$ decreased the most among three W263 mutants. This implies that the hydrogen bond network connecting W263 and D220 is likely to be more involved in $\mathrm{H}_{2} \mathrm{O}_{2}$ binding than electron transfer.

While mutation of W376 to F376 had no effect on the binding of RB19, it affected $\mathrm{H}_{2} \mathrm{O}_{2}$ binding significantly ( $\sim 60 \%$ decrease in binding affinity). This is not surprising as it is only 9.5 and $3.5 \AA$ away from the heme center and W263, respectively. The close proximity of W376 and W263 within Van der Waals distance (3-6 ̊) suggests that an electron transfer could occur between them. The turnover numers of W376F with RB19 and $\mathrm{H}_{2} \mathrm{O}_{2}$ were determined to be 1.3- and 1.4-fold faster than those of the $w t$. Combined with the fact that W376 is responsible for crosslinking in the absence of dye substrates, we concluded that W376 is likely to be involved in off-pathway electron transfer processes. If so, mutation of W376 would be expected to suppress this undesired pathway and thereby increase catalytic efficiency of the enzyme. To test this possibility, a double mutant, W376F/W263F, was constructed and purified. Indeed, the double mutant displayed increased catalytic efficiency 
toward $\mathrm{RB} 19$ and $\mathrm{H}_{2} \mathrm{O}_{2}$ by $80 \%$ and $20 \%$ relative to the $\mathrm{W} 263 \mathrm{~F}$, respectively. The $80 \%$ improvement of the double mutant with RB19 over the single mutant is significant and demonstrates the importance of W376 mutation in biotechnological development of TcDyP applications.

The Y332 is located at the distal side of the heme with a distance of $8.4 \AA$. Because it has a small solvent accessible surface area and is close to the distal cavity where $\mathrm{Fe}^{3+}$ in heme is oxidized by $\mathrm{H}_{2} \mathrm{O}_{2}$, its mutations are predicted to have minimal effects on $\mathrm{RB} 19$ oxidation, but significant impacts on reactions with $\mathrm{H}_{2} \mathrm{O}_{2}$. Indeed, the mutants displayed slightly increased binding affinities with RB19, resulting in improved catalytic efficiency relative to the $w t$. However, the mutations drastically decreased binding affinities with $\mathrm{H}_{2} \mathrm{O}_{2}$ while the turnover numbers increased. In fact, the $\mathrm{Y} 332 \mathrm{~F}$ enzyme had the lowest $\mathrm{H}_{2} \mathrm{O}_{2}$ binding affinity among all mutants shown in Table 1.

\section{Transient-state kinetics of W263, W376, and Y332 mutants in compound I formation and decay}

Since C2LP was assigned as a protein-based radical involving W263, W376, Y332, and others, the corresponding mutants were studied for their transient-state kinetics of compound I formation and decay using a stopped-flow spectrometer. Therefore, the $w t$ and mutant enzymes were mixed with $\mathrm{H}_{2} \mathrm{O}_{2}$ in 1:1 ratio at $\mathrm{pH} 7.8$ and $\mathrm{pH}$ 3.0. Their spectral changes are shown in Figures 8A-D. Analysis of these spectra by Pro-KIV gave a two-step reaction $\mathrm{A} \rightarrow \mathrm{B} \rightarrow \mathrm{C}$ as the best fit. Based on our recent study, ${ }^{12} \mathrm{~A}, \mathrm{~B}$, and $\mathrm{C}$ were assigned as the enzyme resting state (blue lines), compound I (red lines), and C2LP (green lines), respectively. Their spectral character is summarized in Table 2. It has to be pointed out that, while there are minimal effects on the spectral features overall, the C2LP Soret band undergoes a significant blue shift under acidic conditions resulting in an overlap with the Soret band of the enzyme resting state. This spectral overlap therefore limits the accuracy in determining the kinetic parameters of compound I formation and decay at $\mathrm{pH}$ 3.0.

To determine the effect of site-directed mutation on compound I formation, the second-order rate constants $\left(k_{o b s}\right)$ of compound I formation were measured with $w t$ and various mutants at $\mathrm{pH}$ 7.8. The results are summarized in Table 1. While all mutations resulted in the decrease of $k_{o b s}$, the W263A, W376F, and W376F/W263F mutants were diminished the most. This is not surprising because (1) W263 is spatially close to the heme and its mutation to A263 represented a significant change in terms of amino acid structure and property; (2) spectra of the resting states of W376 mutants indicated significant perturbation of the heme microenvironment relative to the other mutants (Figures 8E-F). In addition, the second-order rate constant of compound I formation and overall catalytic efficiency toward RB19 for $w t$ $T c$ DyP were determined to be $4.2 \times 10^{6}$ and $2.3 \times 10^{6} \mathrm{M}^{-1} \mathrm{~s}^{-1}$, respectively, which implied that the formation of compound I was not rate-limiting in the catalytic cycle. This is further supported by the steady-state and transient-state kinetics of W376F. While the rate of compound I formation was slower for this mutant than that of the $w t$, its turnover number toward RB19 was 1.2-fold faster.

The rates of compound I decaying into C2LP $\left(k_{d}\right)$ were also determined for reactions between $5 \mu \mathrm{M}$ enzyme and $5 \mu \mathrm{M} \mathrm{H}_{2} \mathrm{O}_{2}$. As described above, C2LP was assigned as protein- 
based radicals. Since W263, W376, and Y332 were demonstrated to be the radical sites in the presence of $\mathrm{H}_{2} \mathrm{O}_{2}$, mutation of these residues was expected to result in the increase of compound I stability and reduction of decay rates. Indeed, the W263, W376, and Y332 mutants had slower decay rates than the wt. As summarized in Table 1, the decay rates of W263 mutants were $40-50 \%$ of the $w t$, which agrees well with their steady-state kinetics ( $\sim 50 \%$ decrease of $k_{c a t}$ from the $w t$ to mutants).

While multiple residues are involved in the formation of protein-based radicals, W376 should act as the destination of off-pathway electron transfer because it promotes the formation of crosslinking in the absence of dye substrates (Figure 4A). Thus, W376 mutation is predicted to have the largest impact on decay rates among all single mutants. Accordingly, the decay rates of W376 mutants were found to be only $8 \%$ of the $w t$. We found that the $k_{d}$ of Y332 mutants was smaller than expected (from $2.10 \mathrm{~s}^{-1}$ for the $w t$ to $1.80-1.90 \mathrm{~s}^{-1}$ for the Y332 mutants), which is attributed to the neutral $\mathrm{pH}$ of the reaction condition. As discussed above, Y332 only formed radicals when it was oxidized by $\mathrm{H}_{2} \mathrm{O}_{2}$ under acidic conditions (Figure 3C). Thus, mutation of Y332 would minimally affect the compound I stability and its decay rate at $\mathrm{pH} 7.8$.

\section{CONCLUSIONS}

The TcDyP structure solved at $1.75 \AA$ contains two ferredoxin-like folds, which is characteristic of proteins from the DyP family. Catalytic residues D220 and R327 are located at the heme distal side and H312 acts as a proximal ligand to the heme. Although bacterial DyPs display activities toward large-size anthraquinone-based dyes and phenolic lignin model compounds, their modes of oxidation remain unknown. Based on the TcDyP structure, we predicted that $T c \mathrm{DyP}$ uses surface-exposed protein-based radicals for oxidation of large-size substrates. Thus, efforts were focused on aromatic redox-active amino acids that are rich in DyP enzymes. Among 7 tryptophans and 3 tyrosines that are present in the TcDyP, W263, W376, and Y332 are the closest residues to the heme and were identified as the sites of surface-exposed protein radicals, which correspond to a compound II-like product (C2LP) generated from the decay of compound I. In addition, the absolutely conserved W263 in A-class DyPs was also characterized as a surface-exposed substrate oxidation site, which was supported by $\sim 50 \%$ loss of enzyme activity for the mutants and sigmoidal kinetics of TcDyPs toward RB19. W376 was characterized as a major radical sink for the off-pathway electron transfer in the absence of dye substrates, resulting in the formation of protein crosslinks demonstrated by SDS-PAGE, SEC, and significantly slowed decay rates of compound I. Mutation of W376 is beneficial and improves enzyme catalytic efficiency. Sequence alignment revealed that Y332 is highly conserved across all four classes of DyPs. While Y332 was found to function as a surface-exposed protein radical site in $T c$ DyP under acidic conditions, it could not serve as a substrate oxidation site due to its extremely small solvent accessible area. Identification of surface-exposed protein radicals and substrate oxidation sites is important for modulating $T c D y P$ functions and efficiency for improved activity on phenolic lignin. 


\section{Supplementary Material}

Refer to Web version on PubMed Central for supplementary material.

\section{Acknowledgments}

This work is supported by the grants from NIH P30GM110761 pilot project and Johnson Cancer Research Center to P.L., NIH R21AI111203 and R21AI113552 to B.V.G., and NIH U19AI091693 and R03AI122860 and NHMFL UCGP grant 5080 to L.S. Crystal X-ray data were collected at Southeast Regional Collaborative Access Team (SER-CAT) 22-BM beamline at the Advanced Photon Source, Argonne National Laboratory. Use of the Advanced Photon Source was supported by the U. S. Department of Energy, Office of Science, Office of Basic Energy Sciences, under contract no. W-31-109-Eng-38. EPR data were collected at NHMFL supported by the NSF DMR-1157490 and the State of Florida. The authors would like to thank Drs. Chao Chen and David Meekins for helping construct mutant plasmids and prepare Pymol figures, respectively.

\section{References}

1. Singh R, Eltis LD. Arch Biochem Biophys. 2015; 574:56-65. [PubMed: 25743546]

2. Colpa DI, Fraaije MW, van Bloois E. J Ind 1 Microbiol Biot. 2014; 41:1-7.

3. Kim SJ, Shoda M. Appl Environ Microb. 1999; 65:1029-1035.

4. Abdel-Hamid AM, Solbiati JO, Cann IKO. Adv Appl Microbiol. 2013; 82:1-28. [PubMed: 23415151]

5. Pollegioni L, Tonin F, Rosini E. FEBS J. 2015; 282:1190-1213. [PubMed: 25649492]

6. Mukherjee A, Mandal T, Ganguly A, Chatterjee PK. Chembioeng Rev. 2016; 3:86-96.

7. Rabemanolontsoa H, Saka S. Bioresource Technol. 2016; 199:83-91.

8. Bugg TDH, Rahmanpour R. Curr Opin Chem Biol. 2015; 29:10-17. [PubMed: 26121945]

9. Ahmad M, Roberts JN, Hardiman EM, Singh R, Eltis LD, Bugg TDH. Biochemistry. 2011; 50:5096-5107. [PubMed: 21534568]

10. Brown ME, Barros T, Chang MCY. ACS Chem Biol. 2012; 7:2074. [PubMed: 23054399]

11. Min K, Gong G, Woo HM, Kim Y, Um Y. Sci Rep. 2015; 5:8245. Article number. [PubMed: 25650125]

12. Chen C, Shrestha R, Jia K, Gao PF, Geisbrecht BV, Bossmann SH, Shi JS, Li P. J Biol Chem. 2015; 290:23447-23463. [PubMed: 26205819]

13. Koua D, Cerutti L, Falquet L, Sigrist CJA, Theiler G, Hulo N, Dunand C. Nucleic Acids Res. 2009; 37:D261-D266. [PubMed: 18948296]

14. Yoshida T, Sugano Y. Arch Biochem Biophys. 2015; 574:49-55. [PubMed: 25655348]

15. Doyle WA, Blodig W, Veitch NC, Piontek K, Smith AT. Biochemistry. 1998; 37:15097-15105. [PubMed: 9790672]

16. Floudas D, Binder M, Riley R, Barry K, Blanchette RA, Henrissat B, Martinez AT, Otillar R, Spatafora JW, Yadav JS, Aerts A, Benoit I, Boyd A, Carlson A, Copeland A, Coutinho PM, de Vries RP, Ferreira P, Findley K, Foster B, Gaskell J, Glotzer D, Gorecki P, Heitman J, Hesse C, Hori C, Igarashi K, Jurgens JA, Kallen N, Kersten P, Kohler A, Kues U, Kumar TKA, Kuo A, LaButti K, Larrondo LF, Lindquist E, Ling A, Lombard V, Lucas S, Lundell T, Martin R, McLaughlin DJ, Morgenstern I, Morin E, Murat C, Nagy LG, Nolan M, Ohm RA, Patyshakuliyeva A, Rokas A, Ruiz-Duenas FJ, Sabat G, Salamov A, Samejima M, Schmutz J, Slot JC, John FS, Stenlid J, Sun H, Sun S, Syed K, Tsang A, Wiebenga A, Young D, Pisabarro A, Eastwood DC, Martin F, Cullen D, Grigoriev IV, Hibbett DS. Science. 2012; 336:1715-1719. [PubMed: 22745431]

17. Perez-Boada M, Ruiz-Duenas FJ, Pogni R, Basosi R, Choinowski T, Martinez MJ, Piontek K, Martinez AT. J Mol Biol. 2005; 354:385-402. [PubMed: 16246366]

18. Linde D, Pogni R, Canellas M, Lucas F, Guallar V, Baratto MC, Sinicropi A, Saez-Jimenez V, Coscolin C, Romero A, Medrano FJ, Ruiz-Duenas FJ, Martinez AT. Biochem J. 2015; 466:253262. [PubMed: 25495127] 
19. Strittmatter E, Liers C, Ullrich R, Wachter S, Hofrichter M, Plattner DA, Piontek K. J Biol Chem. 2013; 288:4095-4102. [PubMed: 23235158]

20. Strittmatter E, Serrer K, Liers C, Ullrich R, Hofrichter M, Piontek K, Schleicher E, Plattner DA. Arch Biochem Biophys. 2015; 574:75-85. [PubMed: 25542606]

21. Strittmatter E, Wachter S, Liers C, Ullrich R, Hofrichter M, Plattner DA, Piontek K. Arch Biochem Biophys. 2013; 537:161. [PubMed: 23876237]

22. Sugano Y, Matsushima Y, Tsuchiya K, Aoki H, Hirai M, Shoda M. Biodegradation. 2009; 20:433440. [PubMed: 19009358]

23. Sugano Y, Muramatsu R, Ichiyanagi A, Sato T, Shoda M. J Biol Chem. 2007; 282:36652-36658. [PubMed: 17928290]

24. van Bloois E, Pazmino DET, Winter RT, Fraaije MW. Appl Microbiol Biot. 2010; 86:1419-1430.

25. Smith PK, Krohn RI, Hermanson GT, Mallia AK, Gartner FH, Provenzano MD, Fujimoto EK, Goeke NM, Olson BJ, Klenk DC. Anal Biochem. 1985; 150:76-85. [PubMed: 3843705]

26. Berry EA, Trumpower BL. Anal Biochem. 1987; 161:1. [PubMed: 3578775]

27. Adams PD, Afonine PV, Bunkoczi G, Chen VB, Davis IW, Echols N, Headd JJ, Hung LW, Kapral GJ, Grosse-Kunstleve RW, McCoy AJ, Moriarty NW, Oeffner R, Read RJ, Richardson DC, Richardson JS, Terwilliger TC, Zwart PH. Acta Crystallogr D. 2010; 66:213-221. [PubMed: 20124702]

28. Emsley P, Lohkamp B, Scott WG, Cowtan K. Acta Crystallogr D. 2010; 66:486-501. [PubMed: 20383002]

29. Cruickshank PAS, Bolton DR, Robertson DA, Hunter RI, Wylde RJ, Smith GM. Rev Sci Instrum. 2009; 80:103102. Article number. [PubMed: 19895049]

30. Poulos TL. Arch Biochem Biophys. 2010; 500:3-12. [PubMed: 20206121]

31. Veitch NC. Phytochemistry. 2004; 65:249-259. [PubMed: 14751298]

32. Poulos TL. Chem Rev. 2014; 114:3919-3962. [PubMed: 24400737]

33. Sugano Y. Cell Mol Life Sci. 2009; 66:1387-1403. [PubMed: 19099183]

34. Bonini MG, Consolaro MEL, Hart PC, Mao M, de Abreu ALP, Master AM. IUBMB Life. 2014; 66:167-181.

35. Gray HB, Winkler JR. Proc Natl Acad Sci USA. 2015; 112:10920-10925. [PubMed: 26195784]

36. Warren JJ, Ener ME, Vlcek A, Winkler JR, Gray HB. Coordin Chem Rev. 2012; 256:2478-2487.

37. Raven EL, Mauk AG. Adv Inorg Chem. 2001; 51:1-49.

38. Pfister TD, Gengenbach AJ, Syn S, Lu Y. Biochemistry. 2001; 40:14942-14951. [PubMed: 11732914]

39. Linde D, Ruiz-Duenas FJ, Fernandez-Fueyo E, Guallar V, Hammel KE, Pogni R, Martinez AT. Arch Biochem Biophys. 2015; 574:66-74. [PubMed: 25637654]

40. Gengenbach A, Syn S, Wang XT, Lu Y. Biochemistry. 1999; 38:11425-11432. [PubMed: 10471293]

41. Houseman ALP, Doan PE, Goodin DB, Hoffman BM. Biochemistry. 1993; 32:4430-4443. [PubMed: 8386547]

42. Huyett JE, Doan PE, Gurbiel R, Houseman ALP, Sivaraja M, Goodin DB, Hoffman BM. J Am Chem Soc. 1995; 117:9033-9041.

43. Ivancich A, Jakopitsch C, Auer M, Un S, Obinger C. J Am Chem Soc. 2003; 125:14093-14102. [PubMed: 14611246]

44. Ivancich A, Mazza G, Desbois A. Biochemistry. 2001; 40:6860-6866. [PubMed: 11389600]

45. Patterson WR, Poulos TL, Goodin DB. Biochemistry. 1995; 34:4342-4345. [PubMed: 7703248]

46. Benecky MJ, Frew JE, Scowen N, Jones P, Hoffman BM. Biochemistry. 1993; 32:11929-11933. [PubMed: 8218266]

47. Rice RH, Lee YM, Brown WD. Arch Biochem Biophys. 1983; 221:417-427. [PubMed: 6301376]

48. Tew D, Demontellano PRO. J Biol Chem. 1988; 263:17880-17886. [PubMed: 3182873]

49. Uchida T, Sasaki M, Tanaka Y, Ishimorit K. Biochemistry. 2015; 54:6610-6621. [PubMed: 26431465] 
50. Baratto MC, Sinicropi A, Linde D, Saez-Jimenez V, Sorace L, Ruiz-Duenas FJ, Martinez AT, Basosi R, Pogni R. J Phys Chem B. 2015; 119:13583-13592. [PubMed: 26120933]

51. Ilgenfri G, Schuster TM. J Biol Chem. 1974; 249:2959-2973. [PubMed: 4828331] 

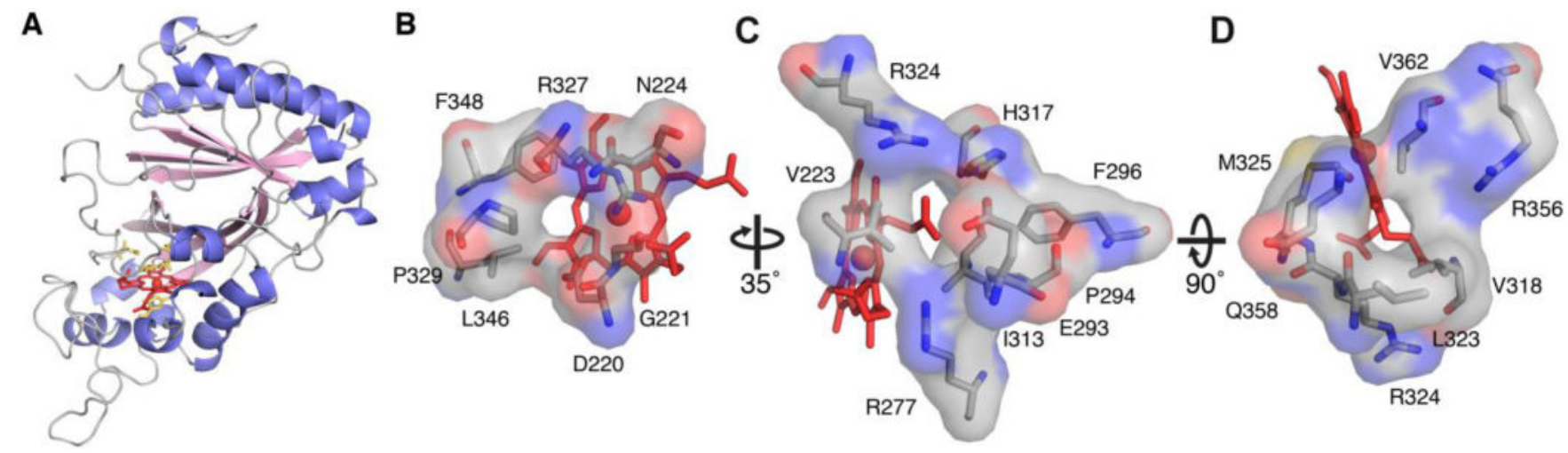

Figure 1.

Structures of $T c$ DyP (PDB: 5JXU). (A) a-Helices, $\beta$-strands, and loops are colored blue, pink, and grey, respectively. The heme porphyrin and catalytic residues are represented as red and yellow sticks, respectively. The heme iron is shown as a red ball; (B) Access channel 1 leading to the heme distal cavity; (C) Access channel 2 pointing to the propionate group on pyrrole ring C; (D) Access channel 3 pointing to the methyl group on pyrrole ring $\mathrm{C}$. 


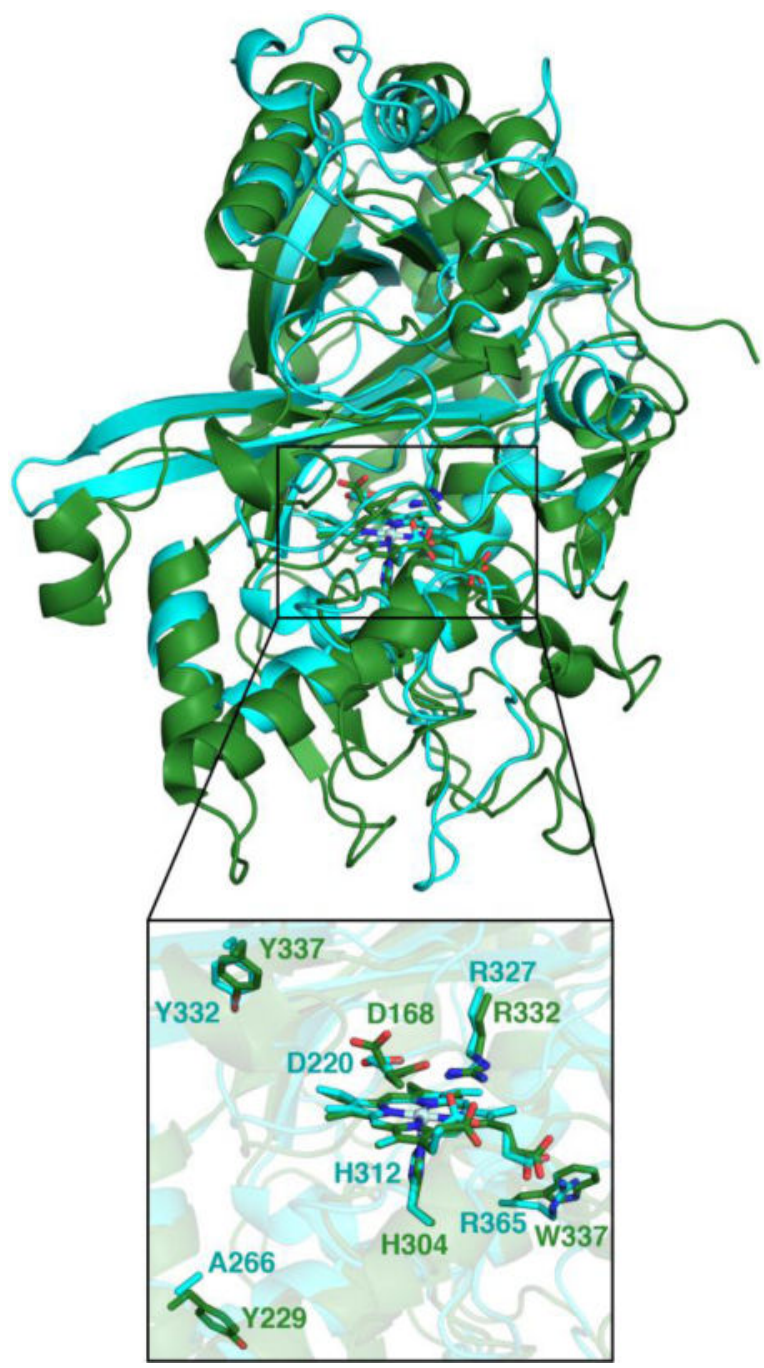

Figure 2.

Structural superimposition of $T c$ DyP (cyan) and AauDyP (green, PDB: 4AU9). Catalytic residues of both enzymes are represented as sticks and labeled. Surface-exposed oxidation sites of $A a u D y P$ and the corresponding residues in $T c \mathrm{DyP}$ are also labeled. 

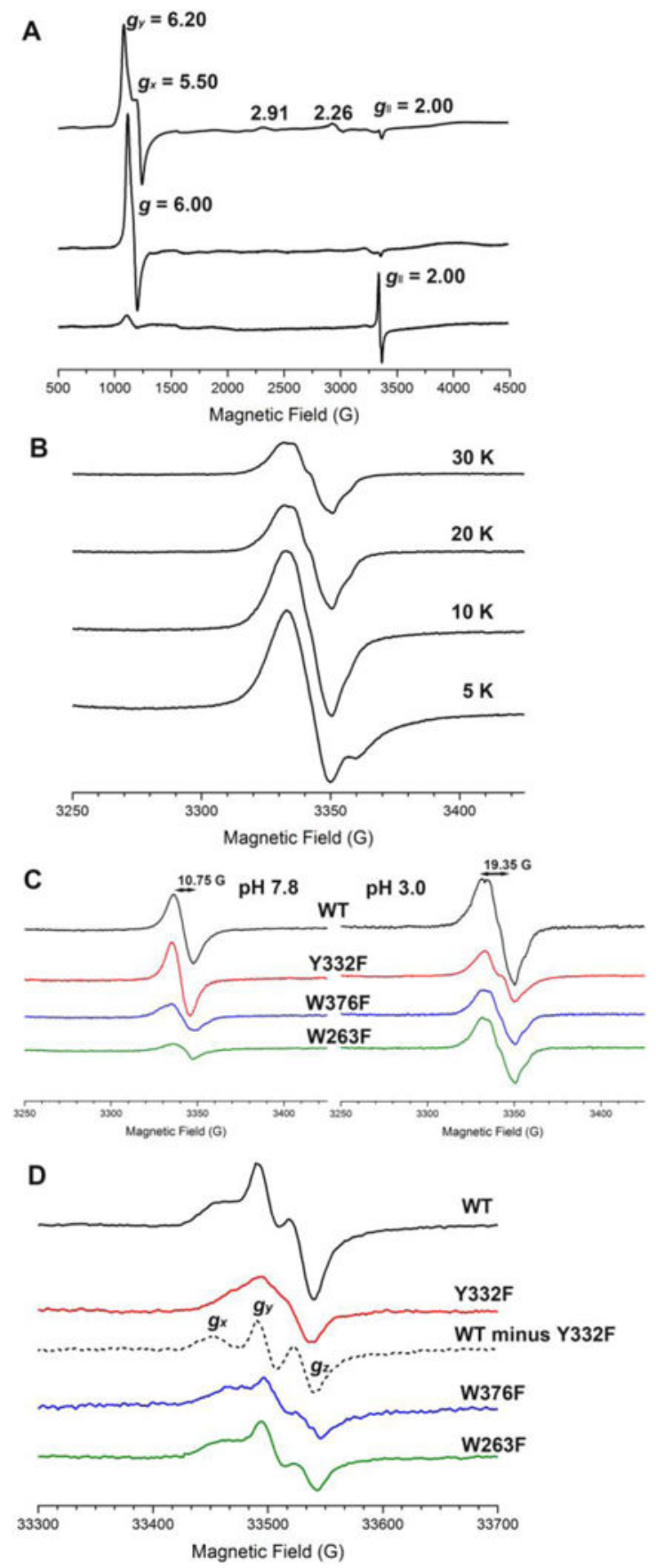

Figure 3.

EPR spectra. (A) X-band spectra of $1.0 \mathrm{mM} w t-T c$ DyP at pH 7.8 (top), $0.1 \mathrm{mM} w t-T c$ DyP at $\mathrm{pH} 3.0$ (center), and $0.1 \mathrm{mM} w t-T c$ DyP plus $1.0 \mathrm{mM} \mathrm{H}_{2} \mathrm{O}_{2}$ at $\mathrm{pH} 3.0$ (bottom) recorded at $5 \mathrm{~K}$; (B) Temperature-dependent X-band spectra of $0.1 \mathrm{mM} w t$-TcDyP reacted with $1.0 \mathrm{mM}$ $\mathrm{H}_{2} \mathrm{O}_{2}$ at $\mathrm{pH} 3.0$; (C) X-band spectra of $1.0 \mathrm{mM} \mathrm{TcDyPs}$ at $\mathrm{pH} 7.8$ (left) and $0.1 \mathrm{mM} T c$ DyPs at $\mathrm{pH} 3.0$ (right) reacted with 10 equiv. $\mathrm{H}_{2} \mathrm{O}_{2}$ recorded at $20 \mathrm{~K}$; (D) W-band spectra of 0.2 $\mathrm{mM} T c$ DyPs reacted with 10 equiv. $\mathrm{H}_{2} \mathrm{O}_{2}$ at $\mathrm{pH} 3.0$ and $30 \mathrm{~K}$. 
A

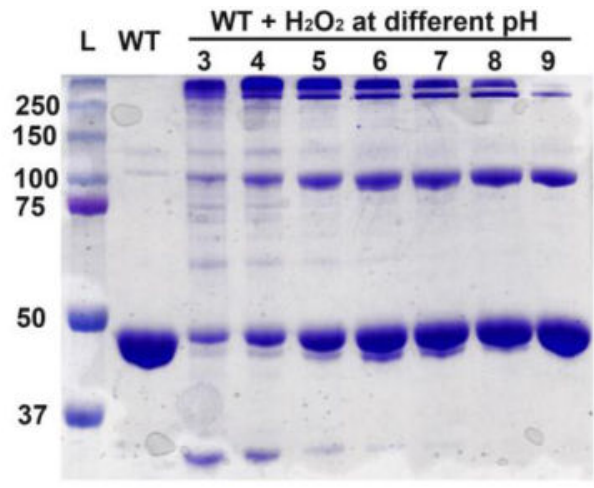

C

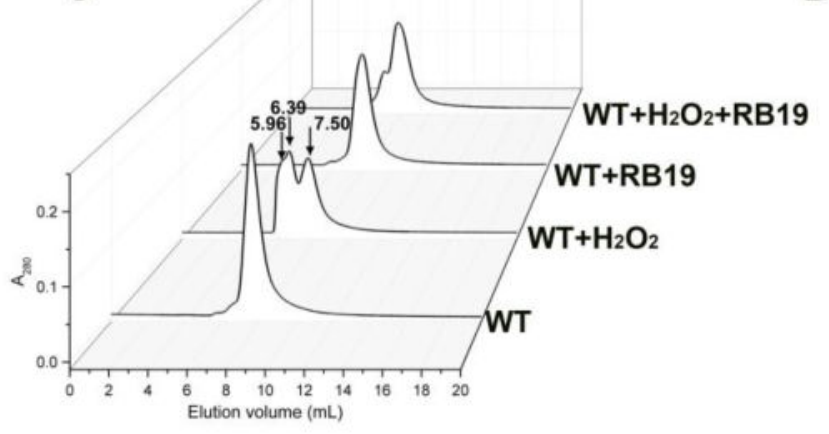

covalent oligomer

covalent dimer

D
B

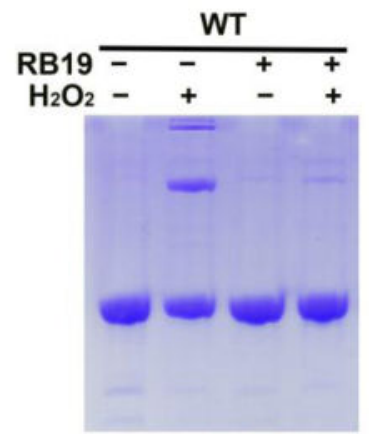

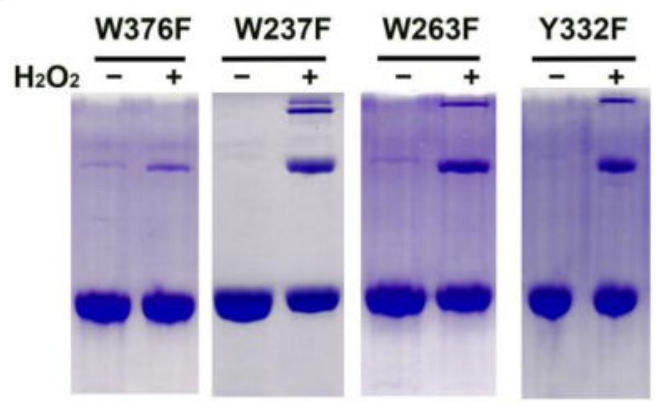
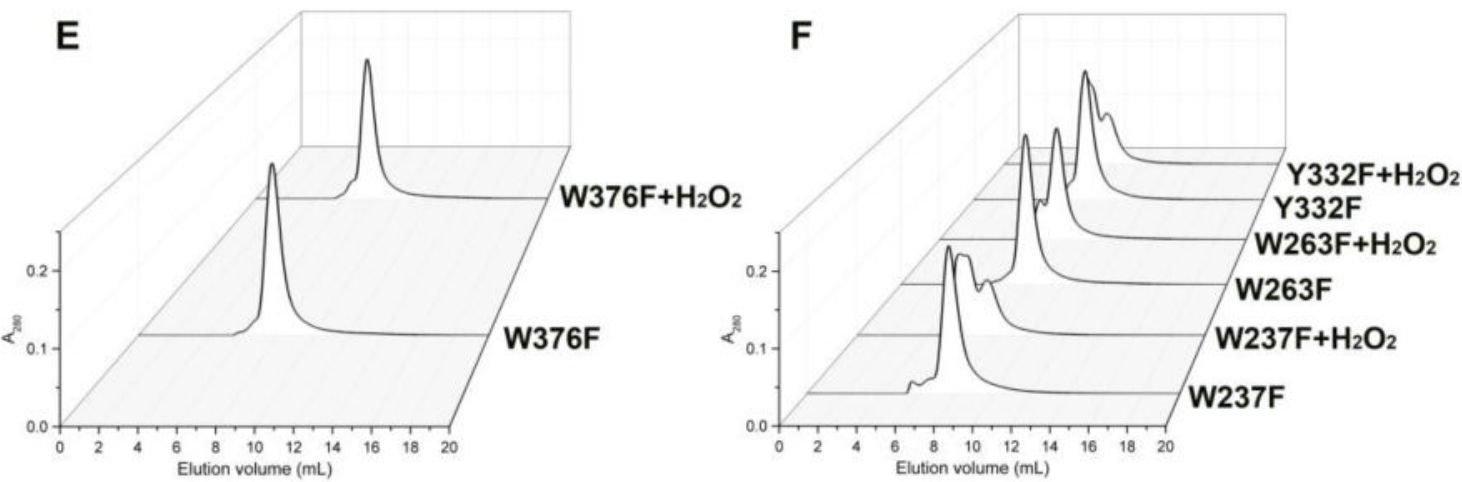

Figure 4.

Analysis of reactions by SDS-PAGE and SEC. (A) SDS-PAGE of reactions between $w t$ $T c$ DyP and $\mathrm{H}_{2} \mathrm{O}_{2}$ under various $\mathrm{pH}$ conditions; (B) SDS-PAGE of reactions between $w t$ TcDyP and $\mathrm{H}_{2} \mathrm{O}_{2}$ in the presence and absence of $\mathrm{RB} 19$ at pH 7.8; (C) SEC of reactions shown in (B); (D) SDS-PAGE of reactions between mutants and $\mathrm{H}_{2} \mathrm{O}_{2}$; (E) SEC of reactions between $\mathrm{W} 376 \mathrm{~F}$ and $\mathrm{H}_{2} \mathrm{O}_{2}$; (F) SEC of reactions between mutants and $\mathrm{H}_{2} \mathrm{O}_{2}$. 


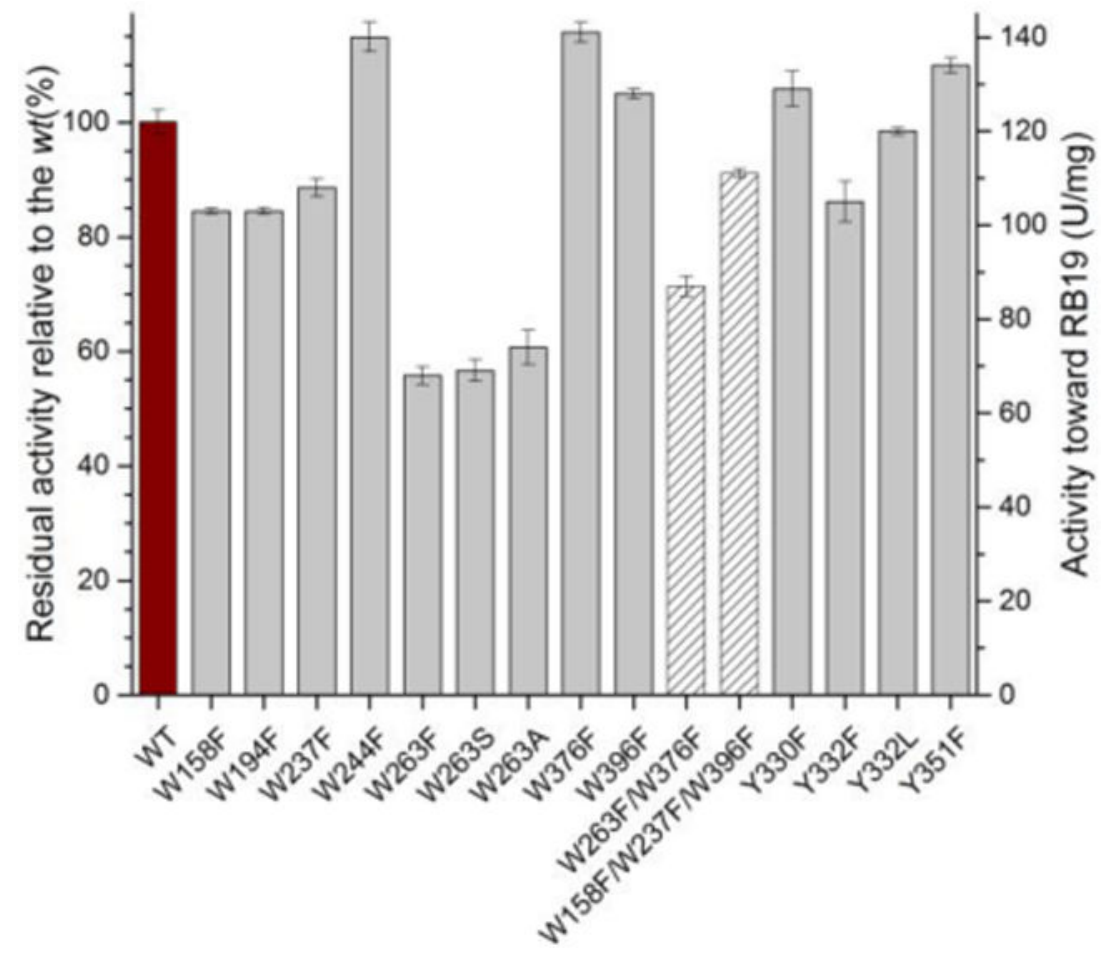

Figure 5.

Residual activities of mutant TcDyPs toward RB19. Red, grey, and patterned bars represent $w t$, single and multiple mutants, respectively. 


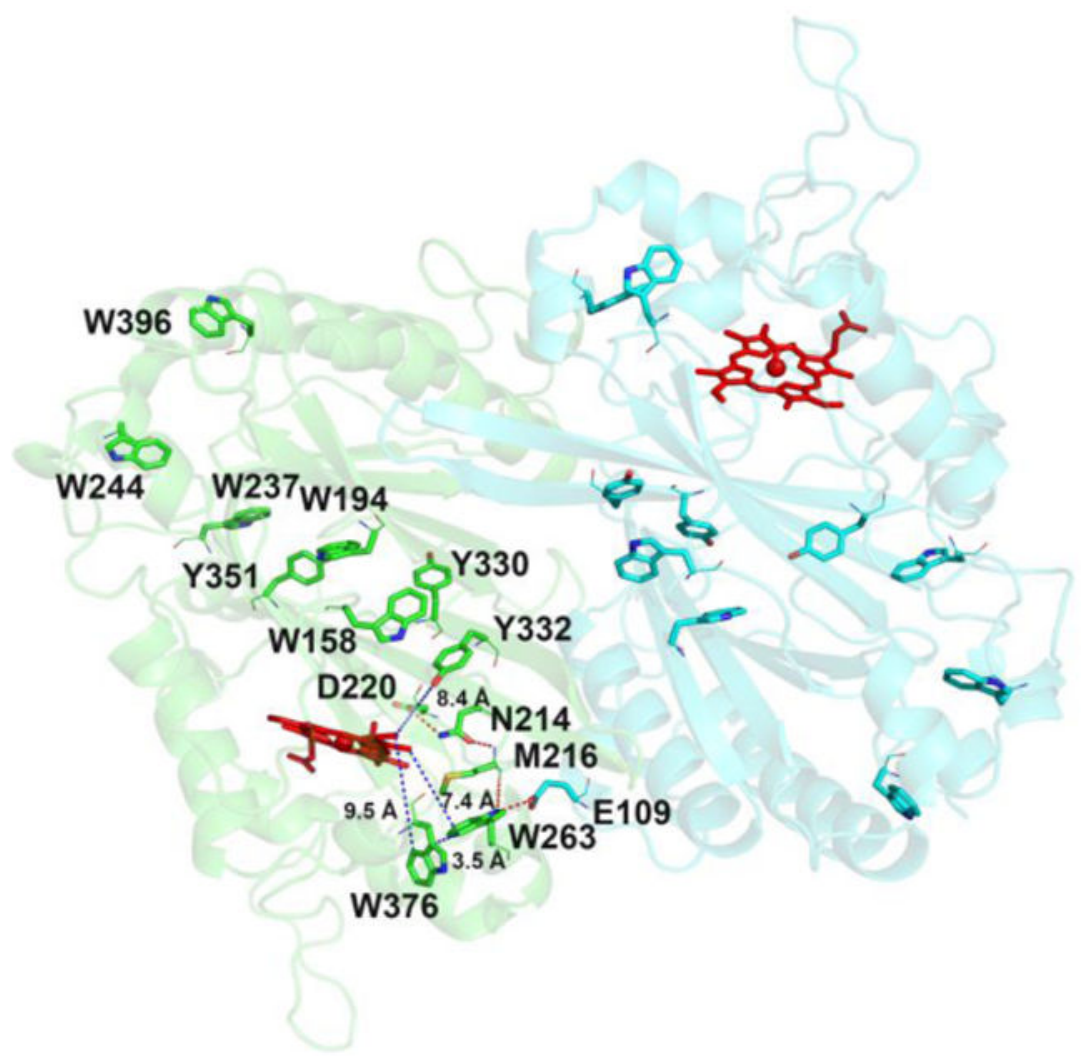

Figure 6.

Location of Trp and Tyr residues in $w t-T c D y P$ and the hydrogen bonding network involving W263. Main and side chains of residues are represented as lines and sticks, respectively. Red and blue dots represent hydrogen bonding and distance, respectively. The two monomeric units are colored in green and cyan. 

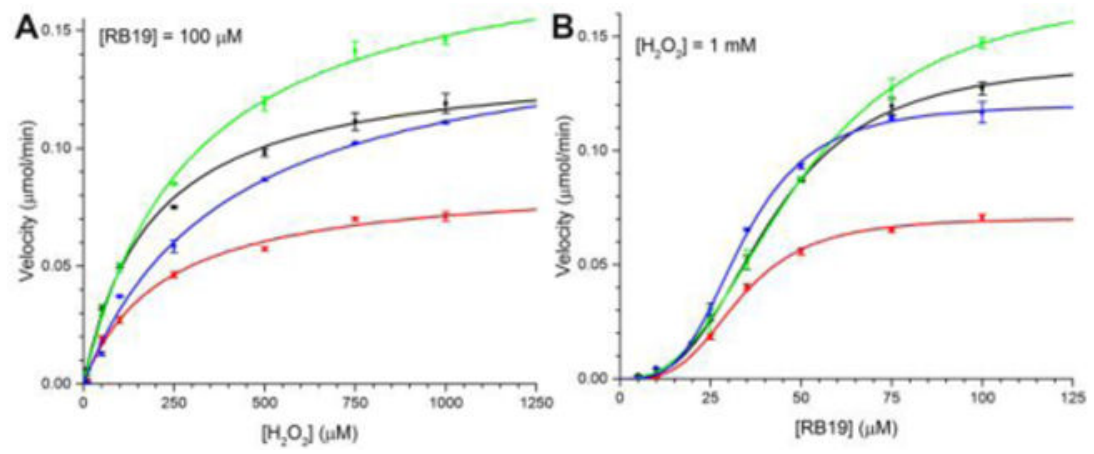

Figure 7.

Steady-state kinetics of $w t$-TcDyP (black), W263F (red), W376F (green), and Y332F (blue). (A) With $\mathrm{H}_{2} \mathrm{O}_{2}$; (B) With RB19. 

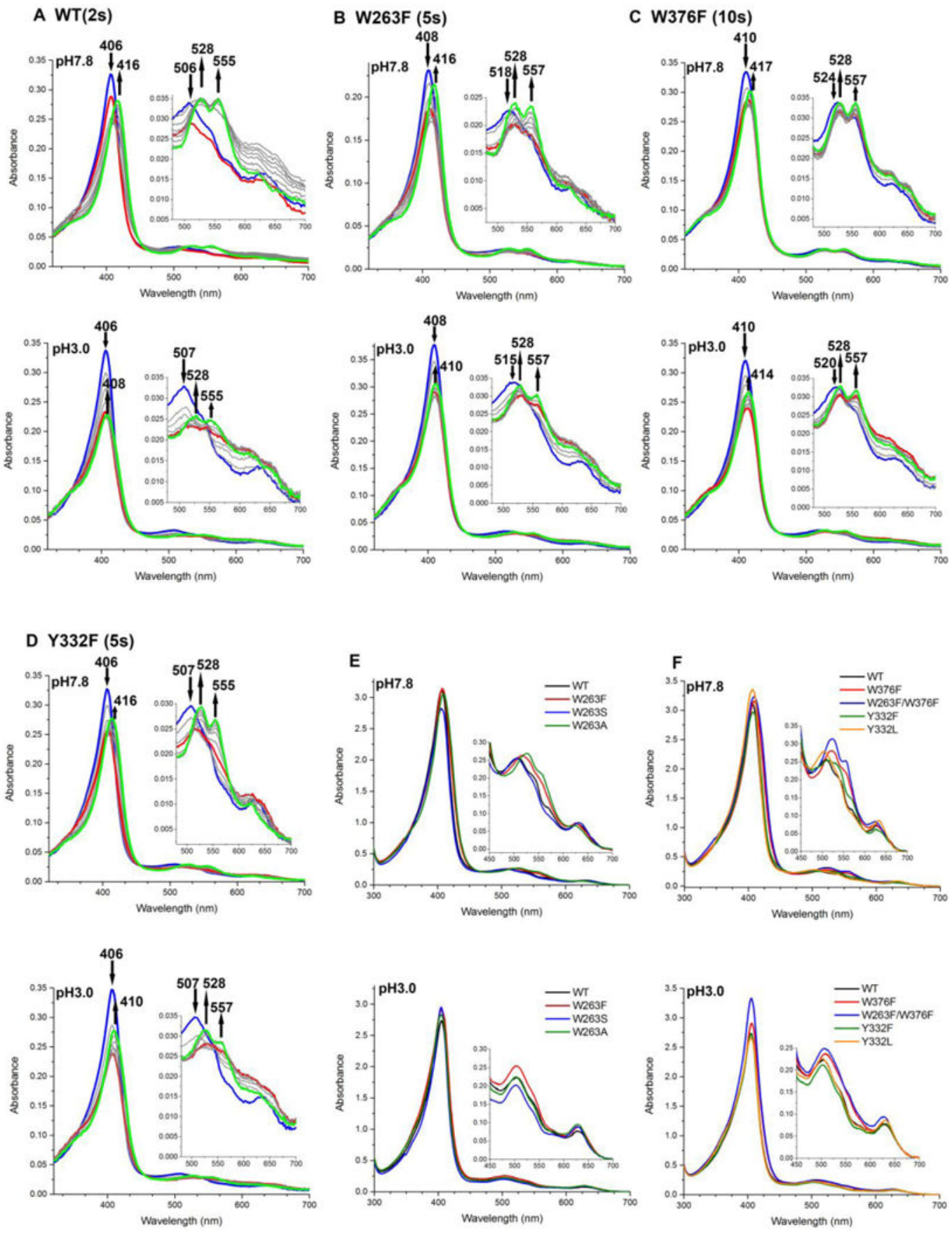

Figure 8.

Stopped-flow spectra of reactions between $T c$ DyPs and $\mathrm{H}_{2} \mathrm{O}_{2}$ at 1:1 ratio (A-D) and spectral overlay of enzyme resting states (E-F). The blue, red, and green lines in A-D represent initial, intermediate, and final states of the enzymes, respectively. Reactions were performed with $5 \mu \mathrm{M}$ enzymes at pH 7.8 (top panel) and 3.0 (bottom panel). Arrows indicate changes of absorbance over time. 


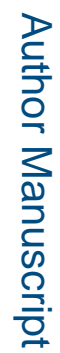

焉

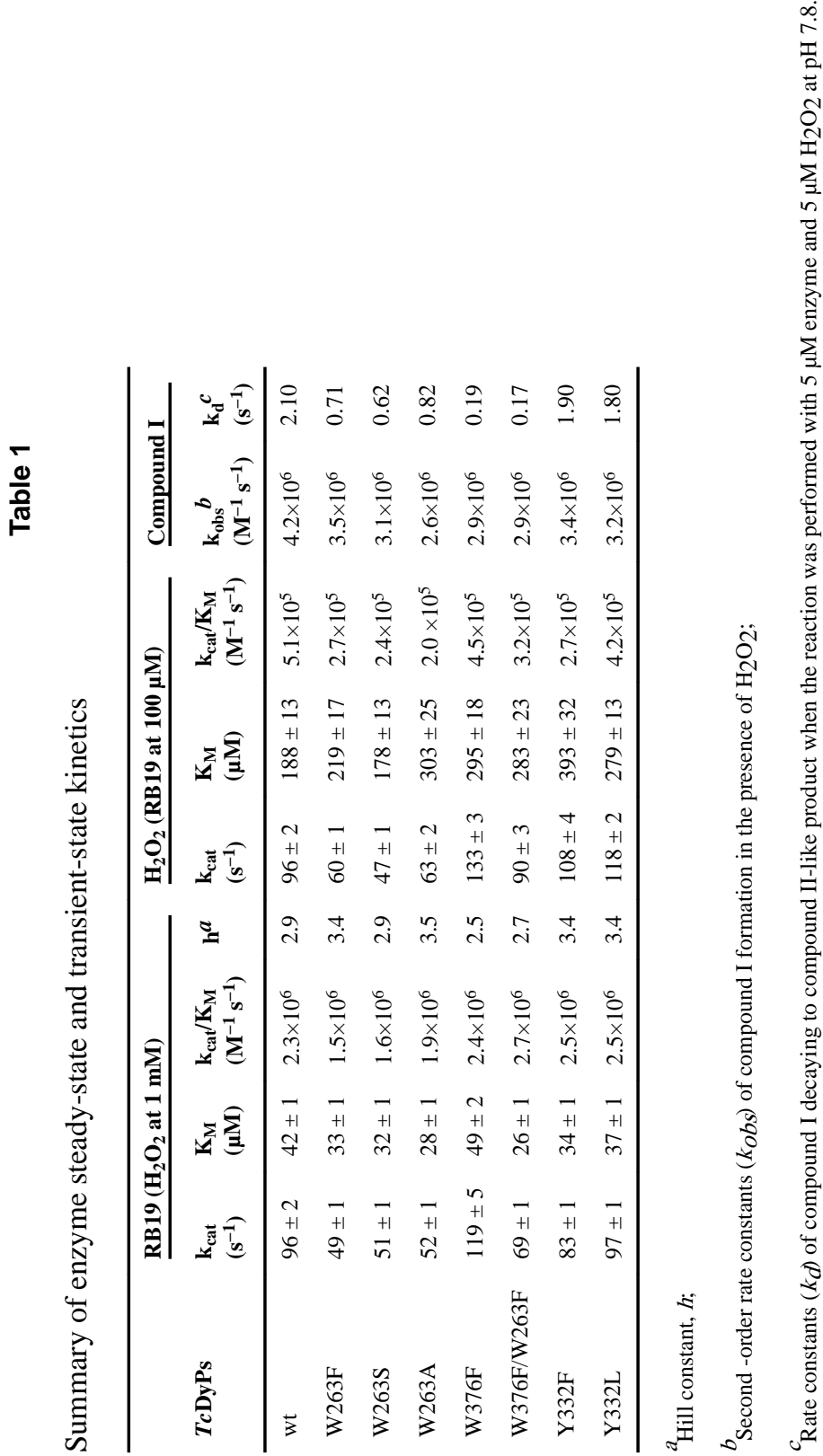

ACS Catal. Author manuscript; available in PMC 2018 January 03. 


\section{Table 2}

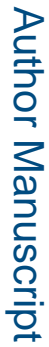

Absorption maxima of resting state and intermediates of $T c \mathrm{DyPs}^{a}$

\begin{tabular}{|c|c|c|c|}
\hline TcDyPs & Resting State & Compound I & C2LP \\
\hline wt & $406,506,545,569(s h), 626$ & $408,524,549,620,650(s h)$ & $416,528,555,619$ \\
\hline W263F & $408,518,553,627$ & $412,530,555,619,648(s h)$ & $416,528,557,621(s h)$ \\
\hline W263S & $407,505,543,632$ & $406,528,614,644$ & $416,528,557,622$ \\
\hline W263A & $408,518,554,628$ & $410,530,555,617,646$ & $418,528,557,621$ \\
\hline W376F & $410,524,553,623(s h)$ & $414,528,555,620,650(s h)$ & $417,528,557,623,649(s h)$ \\
\hline W376F/W263F & $410,524,553,621(s h)$ & $416,528,557,620,652(s h)$ & $418,528,557,619$ \\
\hline $\mathrm{Y} 332 \mathrm{~F}$ & $406,507,540,628$ & $408,523,620,646$ & $416,528,555,622$ \\
\hline Y332L & $406,505,538,629$ & $406,525,616,644$ & $412,526,555,618$ \\
\hline
\end{tabular}

